\title{
Caro Baroja y Galicia
}

Julio Caro Baroja es un etnohistoriador, y dentro de esta línea hay que mirar sus aportaciones al conocimiento de Galicia. Este estudio se divide en dos partes. La primera, de tipo general y teórico, trata de las corrientes intelectuales y de tipo metodológico en que estuvieron inmersos Caro Baroja y los intelectuales gallegos de la Generación Nós y del Seminario de Estudos Galegos. La segunda estudia la visión que tiene de Galicia el autor de Las brujas y su mundo. A pesar de que toda la obra de Caro Baroja es rica en detalles sobre Galicia, aquí sólo se utilizarán fundamentalmente dos obras suyas ${ }^{1}$. Desde que Caro Baroja escribió, algunos puntos de vista son diferentes, pero no se trata aquí de presentar una visión crítica de su obra sino de recordar algo de lo que ha dicho sobre Galicia.

\section{Caro Baroja y la Generactón Nós}

Los autores del Resurximento seguían al pie de la letra las teorías evolucionistas aplicadas a la historia de Galicia. Los de la Generación Nós y el Seminario de Estudos Galegos rompieron con las "simplistas ideas evolucionistas" para adaptar la corriente historicista alemana y la histórico-cultural de la Escuela de Viena, y no aceptaron de sus predecesores gallegos las ideas sobre el celtismo y la romanización de su tierra. Puesto que Caro Baroja, aunque con muchos y complejos matices, se confiesa, en varias y repetidas ocasiones, simpatizante y seguidor de las teorías historicistas, histórico-culturales y de los ciclos culturales se le pueden buscar paralelos metodológicos con los autores gallegos.

Ia Generación Nós y el Seminario de Estudos Galegos son los continuadores de los autores del Resurximento que se inicia con la generación de 1846; hacen un gran esfuerzo por definir la singularidad histórica de Galicia y realizan extrapolaciones atrevidas en cuanto a la historia, el origen de la cultura y de la raza, y a la continuidad de ritos desde sus

1 Los pueblos del Norte de la Península Ibérica (San Sebastián: Txertoa, 1973) y Pueblos de España (Madrid: Istmo, 1981) en adelante PN y PE, respectivamente. 
presupuestos evolucionistas y positivistas. El objeto de su estudio es la totalidad de la cultura en el tiempo y el espacio ${ }^{2}$.

La ley de la evolución es en verdad tan exacta como de antiguo conocida; no quita ni pone, pero nadie dirá que las razas superiores, ni aun en su estado mental más rudimentario, concibieron y expresaron la idea de la divinidad a la manera que las inferiores ${ }^{3}$.

La recuperación de la lengua, del pasado y la concienciación cultural del pueblo fueron las metas pretendidas y, en gran medida, alcanzadas por la Revista y la Generación Nós. Unos cuantos estudiantes de la Universidad de Santiago, preocupados con la idea de conocer su tierra y de aunar esfuerzos para el resurgimiento de la cultura gallega, crearon en 1923 el Seminario de Estudos Galegos, dirigido principalmente a la formación de investigadores ${ }^{4}$.

Los autores de la Generación Nós, dentro de la corriente del historicismo o historia de la cultura y del difusionismo, tratan de encontrar los rasgos de su cultura en los restos históricos y arqueológicos: es la época de la catalogación de los castros, del estudio de la Galicia castreña, en la que se llevan a cabo grande historias, se hacen recopilaciones de refranes, dichos, literatura popular, tratando de explicar su origen histórico. Todo lo que existe viene de algo anterior siguiendo un ritmo determinado; sin creer en el determinismo geográfico y ecológico de manera absoluta, le dan gran importancia 5 .

3 B. VicetTo, Historia de Galicia (Ferrol, 1865), I, p. 260; M. MURGUíA, Galicia (Barcelona: Cortezo, 1888), p. 138; J. RODRÍGUEz LÓPEZ, Supersticiones de Galicia y preocupaciones vulgares (1895). (Lugo: Celta, 1974), pp. 11-12, 23.

3 M. Murguía, Galicia, pp. 140-41.

4 La Revista Nós, una de las manifestaciones más elevadas de la cultura gallega, fue el órgano de expresión del grupo del mismo nombre que nació en Orense impulsado por V. Risco. El número 1 de Nós apareció en octubre de 1920; sus últimos números [139-144], correspondientes a julio-diciembre de 1935, ya no llegaron a aparecer. Cfr. M. MANDIANES, "Vicente Risco y la antropología gallega", Aportaciones a la bistoria de l'Antropologia catalana i bispànica (Barcelona: Generalitat de Catalunya, 1993), pp. 202-219.

5 Los autores de Seminario de Estudos Galegos y de la Generación Nós son conscientes de estar haciendo etnografía y llevan a cabo grandes encuestas que, hoy día, son indispensables para los estudios etnológicos. Utilizaron la encuesta e hicieron trabajo de campo. "Algúns temas foron colleitados con certa facilidade pola existencia dalgunhas monografías sobor diles, que, pese á súa excesiva localización, renderon un bó proveito; máis outros estaban totalmente virxes e o seu estudo non deixóu de presentar certas dificultades que se refirexan no lixeiramente que son tratados [...]. Pra colleital-o material diste traballo, tivemos que pelerinar por todos los camiños da 
Caro Baroja trata de buscar los elementos de la cultura rural actual en la fase prerromana. Está convencido de que en España aún hay que establecer la relación entre el presente y el pasado sin buscar en el pasado, por ello, la explicación de cuanto ocurre en el presente. El hecho de que muchos hayan abusado de este método y lo hayan puesto en ridículo no quiere decir que se deba abandonar el estudio de los rasgos culturales considerados desde un punto de vista histórico, no desde el de su función actual. Está convencido de que los conceptos de ciclo, de ámbito geográfico-cultural y área tienen una gran importancia dentro del método antropológico, aunque con una idea distinta de la que tenía Graebner ${ }^{6}$. Para una sociedad, o un individuo, pueden hoy ocupar estos rasgos distinto lugar al que ocuparon en otras épocas en distintos individuos y sociedades. Los puntos de vista metodológicos de Caro Baroja coinciden básicamente con los de los autores de la Generación Nós, todos estaban inmersos en el historicismo como método de investigación, aunque con matices diferentes.

Tomamos, en suma, la construcción histórico-cultural como principio de trabajo, con las reservas necesarias, y a base de ella procuraremos establecer un área de cultura. La sorpresa que me ha producido el ver que varios elementos culturales que los etnólogos han hallado asociados en los pueblos actuales de los llamados naturales o primitivos, se encuentran asociados en nuestra tierra [...] como fundamento de la cultura actual campesina, es suficiente motivo para justificar la pretensión mía, de dibujar tal área en el mapa de la España prerromana ${ }^{7}$.

Refiriéndose a Los pueblos del Norte, dice:

El libro me sirvió para aclarar muchas cosas y está escrito dentro de un análisis histórico-cultural como ya figura en el subtítulo, pero lo que considero más importante y me ha ayudado para emprender muchas cosas después es el hecho de que un geógrafo del siglo I antes de Cristo como es Estrabón, cuando trató de los

Galiza. Percorrimos a montaña, andivemos polos vales e polas terras chás, visitamolos lugares e andivemos pola veiramar. Fomos informados por homes, por mulleres e por nenos, entramos nas suas casas, visitamol-os seus barcos, os seus obradoiros", X. LOREnZO, "Etnografía. Cultura material, R. OTERO PEDRAYO (dir.), Historia de Galiza (Buenos Aires: Nós, 1962), II, p. 8; cfr. idem, «Nomenclatura del carro gallego", RDTP, XII (1956), p. 55; idem, "Notas pra un cuestionario de etnografía. Embarcaciones", Nós, n. ${ }^{\circ} 111$, p. 49; idem, Cantiqueiro popular da Limia baixa (Galaxia: Vigo, 1973); idem, sobre algunos saludos en gallego", RDTP, XXXII (1976), p. 275; J. TABOADA, Etnografia galega. Cultura espiritual (Galaxia: Vigo, 1972), pp. 16-17; V. RisCO, en R. OTERO, Historia de Galiza (Buenos Aires: Nós, 1962), II, p. 257.

6 PN, p. 12.

PN, p. 31 
pueblos del norte de la Península Ibérica, a pesar de ser un área conocida tan sólo unos años antes por ellos, nos hablaba ya de algo parecido a lo que podemos entender conceptualmente por áreas culturales y que, además, viniesen a coincidir con unos ciclos fijados por Graebner y utilizados por los etnólogos de la Escuela de Viena, sin duda, de manera muy rígida ${ }^{8}$.

Caro Baroja está convencido de que la literatura popular es la flor de la fantasía popular y de la historia, es el sedimento poético de los siglos, que después de haber nutrido los cantos y los relatos continúa viviendo misteriosamente, y de que la mitología greco-latina es el envoltorio y la explicación de la filosofía antigua y sus modalidades estéticas ${ }^{9}$. Después de confesar que no ha tenido la oportunidad de ocuparse a fondo de Galicia, y de reconocer la diferencia de lo gallego dentro del ámbito folklórico peninsular, se pregunta:

¿Quién está mejor capacitado para observar una cultura [...], una sociedad? [...] Una escuela científica o cientifista (lo cual no es lo mismo) dirá, sin vacilar, que el que viene de fuera [...] Esto puede ser verdad. Pero cuando se trata de los escoceses, de los bretones, los vascos o los gallegos, la cuestión es más compleja. Porque, en primer término, no dudamos de que hay grandes escritores de cada grupo de éstos, novelistas y poetas sobre todo, cuya lectura es imprescindible para saber algo de lo que es esencial a tal grupo [...] Podemos aceptar de buen grado, llegado de fuera y armado con métodos modernos será capaz de darnos algunas descripciones muy integradas y ajustadas de un grupo, podrá realzar la existencia de algunos hechos que no se han solido realzar hasta el momento. Su aportación importante no invalidará las otras (las de los nativos), concebidas desde otro punto de vista, incluso los más modestos ${ }^{10}$.

Actuar desconociendo la base sustancial de la vida espiritual, social y económica, guiados exclusivamente por tópicos y teorías, es peligroso ${ }^{11}$.

Estimo que hay que reaccionar fuertemente contra quienes nos dan a entender que los hechos que estudiamos bajo la denominación de folklóricos constituyen

8 J. CARo Baroja y F. J. Flores, Conversaciones en Itzea (Madrid: Alianza, 1991), p. 167; cfr. PE, p. 140.

9 J. CARO BAROJA, Ensayo sobre la literatura de cordel (Barcelona: Círculo de Lectores, 1988), p. 26, y Jardin de flores raras (Barcelona: Seix Barral, 1993), p. 36.

10 J. CARo BARoja, Prólogo, F. Bouza Brey, Etnografía y folklore de Galicia (Vigo: Xerais, 1982), I, p. 7, y Ensayos sobre la cultura popular española (Madrid: Dosbe, 1979), p. 18.

11 El concepto de complejidad es fundamental en la obra de J. Caro Baroja. Una buena parte de las críticas, que repartió a diestra y siniestra, se deben a la mirada miope y reduccionista de muchos autores; cfr. Conversaciones en Itzea, op. cit., pp. 203-206. 
una especie de sistema homogéneo y trabado en la conciencia de cada uno de los individuos de aquella sociedad dentro de la que se registran ${ }^{12}$.

Traditio es lo que viene traído del pasado, transmitido de boca en boca, de generación en generación, y folklore es la ciencia que lo estudia. ¿Cómo imaginar una ciencia del pasado que no sea histórica en gran parte? ¿Cómo ajustar todos sus principios a un criterio exclusivamente funcional, en el sentido utilitario que le dan a la palabra bastantes autores?

La conexión de ciertos sistemas económicos con determinadas formas de la sociedad e ideas resulta evidente, aunque se rechace la determinación de grandes "complejos culturales" válidos para todo el orbe. También parece necesario pensar en la existencia de un principio de evolución oscuro, que impide que lo inventado una vez se olvide absolutamente y que obra de modo interno en cada individuo, con independencia de lo que éste recibe de los que le rodean ${ }^{13}$.

Aunque no cree en el determinismo histórico, Caro Baroja concede una gran importancia a la situación social del hombre a la hora de su nacimiento, de su llegar a ser hombre y a la situación en que escribe y crea sus teorías, es decir, al ámbito personal. Todos los antropólogos observan, pero cada antropólogo está cargado de notas culturales completamente distintas. El abí del ser del hombre comprende también lo que no es el yo; el yo y las circunstancias no se pueden ver como la exposición de dos cosas separadas según pretende Ortega y Gasset y tal vez también Hegel. Esta conceptualización debe ser tenida en cuenta por el antropólogo; cualquier cosa que se proponga estudiar está ante un abi del ser pasado que sería histórico, y un abi del ser presente que se unen en un mismo hombre ${ }^{14}$.

\section{2. la Galicia de Caro Baroja}

Julio Caro Baroja se asomó a Galicia de muchas maneras, pero muy especialmente a través de los clásicos griegos y latinos. De todos modos,

12 J. CARO BAROJA, El carnaval (Madrid: Taurus, 1979), pp. 19-20, y Las formas complejas de la vida religiosa (Madrid: Sarpe, 1985), p. 31.

13 PE, pp. 11-15; PN, p. 241; J. CARO BAROJA, Ensayos sobre la cultura popular..., op. cit., p. 21.

14 Conversaciones en Itzea, op. cit., pp. 130, 154-157; cfr. M. HEIDEGGER, El ser y el tiempo (Trad. de J. Gaos. Madrid: FCE, 1991). Caro Baroja cree que lo que Gaos traduce por el ser abi debería traducirse por el abi del ser. 
no se contenta con resumir lo que dicen los clásicos sobre Galicia, sino que trata de hacer comentarios justos, lo que no es empresa fácil ${ }^{15}$.

En la antigüedad se cultivaba [la antropología], aunque no se conociera el nombre. Respecto a lo que sean investigaciones de lo que se llama Antropología cultural, puede decirse que también se dan anticipos, y que una porción de los pensadores antiguos se plantean la cuestión de los orígenes de la cultura. Como es sabido, las cuestiones de los orígenes dominan gran parte de las ciencias durante el siglo $\mathrm{XIX}^{16}$.

Puesto que se va a tratar de dilucidar las ideas que sobre Galicia tenía Caro Baroja, tal vez lo primero sea saber qué entendía por pueblo. En la obra de Caro Baroja, pueblo es una noción muy compleja que implica, al menos, cierta unidad de costumbres, de creencias, de ideas, de habla y, también, una conciencia, más o menos difusa, de comunidad de origen. El pueblo, a lo largo del tiempo y en un espacio determinado ha ido adquiriendo un conjunto de conocimientos o saberes, de artes y de leyes. Todo ello constituye su configuración, lo que lo distingue de otros:

Toda sociedad, todo conjunto de hombres que vive en un lugar determinado más o menos amplio y que hace un mismo tipo de vida, vive bajo un mismo esquema cultural desarrollando y compartiendo una tecnología, una organización social que comprende desde la familia y vida privada hasta la comunitaria, una educación, unas creencias y prácticas religiosas, unas artes, una lengua ${ }^{17}$.

En general, Caro Baroja admite que Galicia es la región de España más celtizada, pero no tanto como creen los autores de la Generación Nós, ni como, a primera vista, podrían dejar ver los textos clásicos. En cuanto a la romanización, piensa lo contrario; no ha sido tan romanizada como celtizada, pero lo ha sido más de lo que a primera vista pudiera parecer.

15 PN, p. 38.

16 J. CARO BAROJA, La aurora del pensamiento antropológico (Madrid: CSIC, 1983), pp. 9-10. Para consultar lo que dicen los clásicos sobre Galicia, cfr. A. M. ROMERO y X. M. Pose, Galicia nos textos clásicos (Coruña: Caixa de Galicia, 1988). Con respecto a los clásicos, Murguía dice: "Nosotros no hemos inventado a Herodoto, Mela, Plinio, Floro, Estrabón, etc. El texto de estos geógrafos antiguos afirma lo que nosotros consignamos... Al hacer esta evolución, al hacer esta justa historia contra toda la autoridad que han tomado en el tiempo los autores que nos robaron nuestras glorias claro está que la opinión, mal formada... debe rendirse y oponer muchas negaciones a nuestras seguridades", Galicia, op. cit., pp. 140-41.

17 J. CARO BAROJA, y F. J. Flores, Conversaciones en Itzea (Madrid: Alianza, 1991), p. 176; J. CARO BAROJA, Ensayos sobre la cultura popular española, op. cit., p. 16. Cuando se señalen dos o más lugares, la cita literal pertenece a la primera; en las otras se repite la misma idea. 


\subsection{Celtización y matriarcado}

La mayor parte de estos autores del Resurximento y de la Generación Nós defienden que los celtas colonizaron Francia desde España y a ésta desde Galicia. Con el celtismo empezó a tomar cuerpo un cierto regionalismo. Defienden que la sangre de los gallegos es celto-sueva, que los castros son celtas y que éstos invadieron la Galia desde Galicia. M. Murguía sostiene la estrecha relación entre la filosofía y la historia y la existencia de las razas puras, esto se confirma con la realidad gallega. Ayuda a la conservación de las razas puras el hecho de que la naturaleza tiende a conservarse, dice el autor aludiendo a Bérard. Los cruzamientos fueron hasta un momento sin importancia y siempre en detrimento de las razas inferiores ${ }^{18}$.

Los autores de la Generación Nós identifican la capacidad creadora de un pueblo con su grado de desarrollo. Privilegian el factor cultural por encima de todo, porque la vitalidad de cualquier pueblo y su capacidad de nacionalismo se confunden con su capacidad y con su dinamismo culturales.

Tenemos una fe ciega, absoluta e inquebrantable en la vitalidad y en el genio de nuestra raza, [...] Los colaboradores de Nós pueden ser lo que les parezca [...] con tal de que pongan por encima de todo el sentimiento de la tierra y de la raza [...] Nós ha de ser un estudio [...] de todos los valores gallegos [...], la afirmación para siempre del verdadero ser de Galicia, del enxebrismo [...] que es nuestra originalidad específica, nuestra capacidad de creación, nuestro autóctono dinamismo mental. [El sentimiento de la tierra madre es] el sentimiento religioso [y pagano; se traduce en apego a la región y configura el sentido estético de los gallegos de origen celto-ario]. En donde no hay cultura no hay pueblo ${ }^{19}$.

Caro Baroja, después de hacerse eco de lo que los autores románticos y de la Generación Nós y el Seminario de Estudos Galegos dicen sobre celtización, se muestra crítico con su teoría. Según él, la celtización, de la que hay también algunas huellas entre los cántabros y en Vasconia, puede haber sido menos intensa de lo que podría pensarse, dado que estas casas de planta redonda, que algunos consideran celtas, no es seguro que lo sean. La invasión o invasiones célticas de Galicia fueron del tipo más

18 B. VICETTO, Historia de Galicia, I (Ferrol, 1865), pp. 8, 10, 114, 132-133; M. MURGUíA, Galicia (Barcelona: Est. Tipo.-Edit. D. Cortezo, 1888), pp. XIV, 8, 10, 20-21, 3334, 61, 237-38, 251, 447; R. MAf́, O regionalismo galego; organización e ideoloxía (18861907) (Coruña: Publicaciones do Seminario de Estudos Galegos-Ed. do Castro, 1984).

19 Nós, 1 (1920), pp. 1-2. 
absoluto, disfrutando los invasores de las mayores ventajas y ejerciendo dominio sobre la población antigua en general. Los galaicos de la época de Estrabón son un pueblo céltico, mucho más que sus vecinos los astures y los cántabros; pero no son un pueblo absolutamente celta. La distinción entre galos y celtas, que se presta a muchos equívocos, ya que ambas palabras parecen del mismo origen, ofrece un matiz variado desde un punto de vista histórico. El nombre de Galicia podría confundirse con el de Gallia, pero muchos autores clásicos la llaman Callaecia - y a sus habitantes callaicis-y no Gallaecia y gallegos. En realidad no se sabe a qué se debe el atribuirle nombres distintos ${ }^{20}$.

Caro Baroja defiende que Galicia es el pueblo más celta de toda la Península, pero, aun así, no tanto como se suele decir. Para los antiguos, en ocasiones, los cántabros, los astures, los várdulos o los vascones son una gens. Pero, en otras ocasiones, se habla de gentes distintas dentro de estas grandes divisiones, lo que crea desconfianza sobre el valor que pueda darse a la palabra latina. En la parte occidental del área nórdica de la Península, ocupada por astures y galaicos, los elementos célticos son muy intensos. Aunque Silio Itálico habla de las lenguas nativas de los galaicos, y Plinio separa los célticos y los lemavos del Convento Lucense de otros pueblos de nombre dificultoso, no hay modo de precisar la filiación de éstos. Se puede decir que son protoceltas, pero no muy emparentados con los vascoaquitanos puros. Sin embargo, entre los habitantes de un extremo y los del otro hay algo en común muy difícil de determinar. Desde el punto de vista arqueológico, Galicia tiene, con el norte de Portugal, unidad muy definida que la diferencia sensiblemente de los otros países de la zona septentrional; desde el puramente lingüístico, el idioma gallego es suficiente para reforzar esta idea de unidad. Más difícil sería hallarla en la investigación de los rasgos físicos, que se han solido considerar, un poco a la ligera, como los más representativamente celtas de la Península: aunque hay tipos definidos de gallegos, éstos son variados ${ }^{21}$.

La romanización de las provincias gallegas fue mayor de lo que a primera vista pudiera parecer, aunque perduró el régimen antiguo de población. Una buena parte de los castros habitados de tipo prehistórico fueron construidos en época romana tardía. Según el obispo Hidacio, con la llegada de los bárbaros, los nativos se refugiaron en las civitates, centros comerciales ${ }^{22}$. Muchos de los habitantes de la Lusitania vivían en las montañas, tierras estériles e inaccesibles a los ejércitos romanos, bajaban

20 PE, I, pp. 162-164.

21 PE, I, pp. 353-354, 372; II, pp. 151-152.

22 PE, I, p. 405. 
a los valles a saquear las ciudades, a robar y pillar. Una vez, César les tendió una trampa, les dijo que bajaran, que les entregaría tierras fértiles y acabó con una enorme multitud. Se trataría de un movimiento de rebeldía de clases sociales desamparadas, la de los pastores y cazadores de tierras fragosas, esclavos y mozos sin fortuna, contra gentes pudientes.

La inspección del trabajo en minas, los viajes de reclutas y otras comisiones fueron con probabilidad las causas únicas de que los romanos con cargos superiores franquearan los montes de la depresión vasca de vez en cuando. En el territorio montañoso de Asturias, León y E. de Galicia la explotación de los yacimientos auríferos debió de influir para que hubiera algunos focos más de cultura romana ${ }^{23}$.

Refiriéndose a los pueblos del norte de la Península Ibérica de la época prerromana, Caro Baroja dice: "la existencia de unidades sociales mayores que la familia, basadas en la idea de un supuesto parentesco, está ampliamente documentada" ${ }^{24}$. ¿Cómo establecían el parentesco, la gens? Los datos recogidos sobre la herencia matrilineal y el matrilocalismo hacen pensar que eran uterinos, pero la práctica de la covada hace dudar. Tal vez en el momento en que estos datos eran recogidos, especialmente por Estrabón, las cosas ya estuvieran cambiando. Los habitantes, cuando obtenían cierta cantidad de vino y de comida, la consumían reunidos todos los parientes sentados en ć́rculo, en bancos adheridos a los muros de las casas. Se pasaban unos a otros la comida, ocupando los puestos según la edad, que era muy respetada. Un consejo de ancianos ostentaba la máxima autoridad en las deliberaciones que afectaran a la comunidad; otros adquirían la dignidad por valor, inteligencia. Con todo, parece ser que muchos viejos, cuando se daban cuenta de que no eran útiles para la guerra, se envenenaban ${ }^{25}$. También cree que ciertos elementos actuales de sectores sociales determinados, derivan de sociedades antiguas:

En lo relativo a vestigios de las antiguas unidades sociales, es claro que nada o casi nada queda ahora. Hay, sin embargo, ciertos datos de un pasado más o menos cercano, de épocas situadas entre la nuestra y la romana referentes a instituciones que se pueden interpretar como residuos de las viejas divisiones. Los bandos medievales de las provincias vascongadas, Santander, Galicia, etc., bandos en los que se encuadran diferentes familias o linajes de pueblos distintos, unidos por lazos de sangre, es muy posible que tuvieran su origen en una organización por unidades semejantes ${ }^{26}$.

23 PE, I, pp. 115-116, 332-334.

24 PE, I, p. 352.

25 PE, I, pp. 352-353.

26 PN, pp. 228-231. 
A propósito de la covada dice que cuando las mujeres parían, mandaban acostar en su lugar a los maridos y los cuidaban. J. Caro Baroja defiende que Estrabón sólo habla del norte de España, contra la opinión de Schulten, que cree que se refiere a toda la Península Ibérica. Aunque el autor diferencia a los cántabros de los otros pueblos del Norte, admite y defiende un gran parecido, por no decir identidad, entre ellos. Todos son montañeses, y aunque Estrabón no fue un ciego admirador de la teoría de que el medio hace al hombre, en este caso la utiliza para explicar la manera de ser de la gente del Norte. De la covada cree que fue una práctica que existió, tal como la describe Estrabón, y se practicó desde los Pirineos a Galicia, sin negar que también otros pueblos la hayan practicado ${ }^{27}$. Caro Baroja la interpreta así:

[La covada] tiene alguna relación con una serie de creencias ligadas con la estructura de la familia en un momento dado: que el hombre, cuando su mujer da a luz, cumple una serie de preceptos [...], está destinado a hacer resaltar sus relaciones y derechos [...] No creo que esta moda o costumbre tenga la importancia general que se le ha querido dar a partir de Tylor, pero parece evidente que no puede provenir más que de la idea de la participación del hombre en el acto de la procreación y que, según desde qué punto de vista se practique, puede tener una significación $\mathrm{u}$ otra, puede ser un acto jurídico o puede ser un acto mágico ${ }^{28}$.

En Galicia, las mujeres tomaban parte considerable en las faenas del campo; conducían el arado, escardaban, sembraban, estercolaban y hacían la seitura (siega) como los hombres.

Vemos, pues, por estas breves noticias, que hasta el presente se han conservado vestigios de las más primitivas formas de la agricultura en una zona importante del N. de España. Ya no son las mujeres, como antes de la romanización, las únicas que trabajaban en el campo, pero todavía, en general, intervienen en las faenas tanto como los hombres, habiendo, además, ciertas particularidades locales en la división del trabajo ${ }^{29}$.

En algunas zonas del Norte, los ritos de paso han tenido gran interés hasta no hace mucho tiempo. Las bodas, los funerales y los bautizos son todavía

27 PN, pp. 35-51, 224-225 y PE, p. 349. Cfr. PN, p. 214, nota 118; Estrabón, III, 4, 17-18; Justino, XIIV, 3, 7; Silio Itálico, III, 344-353. Para demostrar la existencia de las prácticas de la covada hasta no hace mucho tiempo, hace alusión a las fichas de la Encuesta del Ateneo de Madrid de 1901 sobre el ciclo de vida, PN, p. 227.

28 PN, pp. $13-52$ y 226.

29 PN, I, pp. 151-164 y PE, II, pp. 159-164. Cita a N. TENORIO, La aldea Gallega (Cádiz, 1914), pp. 35-40; L. H. ROBREDO, "Cómo es y cómo vive la labradora gallega", Hojas divulgadoras (Madrid: Ministerio de Agricultura), XXXI, 1 (1936), pp. 3-14; E. GIL, "El segador", Los españoles pintados por si mismos, pp. 211-213. 
los momentos de la vida en los que se reúne toda la parentela. Los funerales, en que se han hecho constantemente excesos de comida y de bebida, fueron causa de severas leyes represivas con resultados escasos. También otros autores hablan con asombro de la fortaleza de las mujeres del norte de España. Eran ellas las que trabajaban; los hombres no se ocupaban más que de la guerra y del latrocinio. Según Caro Baroja, la organización familiar matrilocal y matrilineal existía en todos los territorios que Estrabón considera como de vida parecida y no sólo entre los cántabros, como pretende el griego ${ }^{30}$. Estrabón nos dice que, entre los cántabros, el hombre dotaba a la mujer, las hijas heredaban y eran las que daban mujer a sus hermanos. "Todo esto - añade - producía una especie de ginecocracia no demasiado civilizada" 31 . Para explicar ciertos "desórdenes" sexuales que tienen lugar en determinadas fechas del calendario y en los banquetes, Caro Baroja dice:

\begin{abstract}
Estas costumbres pueden relacionarse muy bien con las de licencia sexual y de vida particular de los solteros en parejas, en determinadas chozas y graneros, que los etnólogos han encontrado en pueblos agrícolas y matriarcales, como los del NO de Melanesia, tan hermosamente descritos por Malinowski. [...] Este investigador famoso [...] con sus descripciones de las costumbres de los naturales de los archipiélagos de Nueva Guinea, me hace pensar que los convites de toda la parentela a que alude Estrabón, en que se consumía el vino cogido, tendrían un carácter más trascendental del que a primera vista pudiera asignárseles ${ }^{32}$.
\end{abstract}

\title{
2.2. Hábitat, tecnología y economía
}

En la zona occidental de Galicia priva la pequeña aldea; en el sureste las aldeas son grandes y están distanciadas unas de otras, y en el norte y

30 PN, pp. 214 y siguientes.

31 PE, I, p. 349.

32 PN, pp. 213-214. Cita a MALINowsKI, Argonauts of the Pacific (Londres, 1922), pp. 169-172. Este uso que hace Caro Baroja, aquí y en otras muchas partes, de autores que nada tienen que ver con Galicia, se entenderá muy bien si se tiene en cuenta que el difusionismo, escuela a la que se sentía próximo, ve en la coincidencia cultural el resultado de un préstamo hecho por una de las culturas. Los difusionistas no dudan en poner en paralelo rasgos culturales muy alejados en el espacio o muy distantes en el tiempo; una innovación nace en un lugar determinado y desde allí, por difusión, se extiende. Todas las culturas pueden definirse como el resultado de contactos con otras, debidos a las migraciones; con todo, una cultura nunca es aceptada por otro grupo sin someterla a profundos cambios y los trazos menos importantes se pierden a lo largo del proceso. Otros, más moderados, hablan del préstamo cultural que puede transformar, deformar, hipertrofiar tal o cual elemento prestado, transferirlo en un plano simbólico, tomar un cuadro formal y llenarlo de un contenido diferente; es decir, es susceptible de adaptación al medio. 
centro, la dispersión es intensa. En las montañas lindantes con León hallamos los tipos de construcción permanente más primitivos de todo el norte, las pallozas. Aunque ostentan variantes según las descripciones de los diferentes autores, todos reconocen su relación estrecha con las casas circulares prehistóricas.

Tiene pared de piedra muy baja y circular o redondeada, y enorme techo cónico de paja, sin chimenea alguna. Dentro apenas si hay otras divisiones que las hechas con unos maderos. Los muros no tienen más de sesenta centímetros de grosor y son de lajas de pizarra. Se reparten sin orden ni concierto en un recinto convenientemente defendido ${ }^{33}$.

Las casas de planta circular, que suelen tener un pequeño vestibulo o pasillo a la entrada, probablemente estaban cubiertas de paja, a la manera de las que en la actualidad hay habitadas en las montañas de León y Orense. Como complemento, no lejos de ellas hay unas casetas para guardar aperos y utensilios. También las hay rectangulares, con los ángulos redondeados y trapezoidales. La zona arqueológica donde existen los castros casi coincide con la zona etnográfica, aunque es más amplia. Se trata de una forma fundamentalmente pastoril, con precedentes en culturas más arcaicas y puede relacionarse con los apriscos a modo de tholos que construyen los pastores de muchas regiones de España ${ }^{34}$.

Pero el análisis de su forma no nos dice gran cosa sobre el pueblo que la creó o trajo, dígase lo que se diga, pues si bien es cierto que en la zona del Rhin hay casas circulares, a lo largo del Mediterráneo hay construcciones semejantes a las de las brañas, que nadie podría considerar como celtas ${ }^{35}$.

Cerca están el hórreo y el pajar. Los tejados, al menos en parte de las provincias de Lugo y Orense, son de pizarra. Repartidos por toda la geo-

33 PN, pp. 87-88.

34 PE, II, p. 152. El autor cita a F. KRÜGER, La cultura popular en Sanabria (Zamora: Caja España, 1991) y "Las brañas", Bol. del Inst. de Est. Asturianos (1949); A. del Castillo, "Por las montañas de Galicia. Las casas del Cebrero", Boletín de la Real Academia Gallega, VIII (1913), pp. 147-154 y "Origen y antigüedad de las pallozas del Cebrero", ibid., IX (1914), pp. 241-248; L. CRESPI, "Contribución al folklore gallego", Conferencias y reseñas (Tom. IV. Madrid: Real Soc. Esp. de Historia Natural, 1929), 19 pp.; A. García BelLido, "Sobre la casa redonda", RDTP, XXII (1967), pp. 41-54 y "El castro de Coaña", Archivo español de Arqueología, 48 (1942), pp. 216-244. Publicado recientemente en A. GARCía BELLIDO, Urbanistica de las grandes ciudades del mundo antiguo (Madrid: CSIC, 1985), pp. 269-311.

35 PN, pp. 241-242. 
grafía gallega, están los pazos, "palacios lujosos" ${ }^{36}$, muchos de ellos, y por avatares de la vida, se convirtieron en residencia de campesinos no tan acomodados. Hay otros tipos de casa, parecidos a los de otras partes de España ${ }^{37}$.

Las casas de zonas menos abruptas suelen ser de piedra, a veces de grandes bloques, otras de mampostería sin encalar, de una sola planta las más pobres, con un piso las de los aldeanos de origen pudiente. A veces tienen galerías [...] y escalera exterior. El hogar, lareira, se halla en la planta baja y alrededor de él se reparten los dormitorios en forma de pequeños departamentos o camarotes. En comunicación con él se halla el establo o corte. En el piso alto suele estar el desván o sobrado y alguna cámara que se usa como dormitorio ${ }^{38}$.

El área en que se señala la existencia de los aperos de labranza primitivos y los cultivos elementales, limitada al S. por aquella en que aparecen casos de colectivismo agrario, es también el área de difusión del hórreo y construcciones afines. Si aperos tales como la laya y la azada nos permiten reconstruir la economía del complejo prerromano con cierta precisión, el hórreo, con su forma característica, nos confirma la existencia del mismo complejo de agricultores arcaicos. Los hórreos gallegos sólo sirven para guardar maíz, que se cura en el interior, mientras que el asturiano sirve de despensa y granero, curándose el maíz en el exterior. Los tipos de hórreos gallegos se extienden también por Portugal, entre Miño y Duero, y se les llama espigueiros. El cabazo (hórreo de ramas entretejidas) es de planta circular y propio del occidente asturiano y de Galicia. Ya en la época prerromana, los hórreos desempeñaban las funciones que conservan en la actualidad ${ }^{39}$.

Los cereales principales son la cebada (de la que hacían cerveza), el centeno y el millo, nombre con que más tarde se llamó el maíz venido

36 PE, II, p. 154.

37 PE, II, p. 155. Cita a N. TENORIO, La aldea gallega; MARQuÉs DE QUINTANAR y otros, Los pazos gallegos (Vigo, 1928); M. DURÁN, "La casa compostelanan, Arte Espanol, VII (1926), pp. 5-8; V. RIsco, Terra de Melide (Santiago: Seminario de Est. Galegos, 1933), pp. 325-335; F. LóPEz CuEvillas y J. LORENZO, Vila de Clavos de Randín (Santiago: Seminario de Est. Galegos, 1930); F. LÓPEZ CuEVILlas, J. LORENZO y V. FERNÁNDEZ, Parroquia de Velle (Santiago: Seminario de Est. Galegos, 1936).

38 PE, II, p. 153.

39 PN, pp. 165-173; PE, II, pp. 163-164. La información histórica sobre el tema la obtiene de E. FrankowsKI, Hórreos y palafitos de la Peninsula Ibérica (Madrid: Museo Nacional de Ciencias Naturales, 1918); VARRón, Rerum rusticarum libri tres, I, 57, 3; J. LÓPEZ SOLER, "Los hórreos gallegos", Actas y Memorias de la Sociedad Española de Antropología, X (1931), pp. 97-161. 
de América. En el tiempo en que se escribió Los Pueblos del Norte, en Galicia aún se desgranaban los cereales con el mayal o golpeando las gavillas contra una piedra. "El carro chillón de ruedas unidas al eje" ${ }^{40}$, más viejo que el de ruedas radiales y con variantes según las regiones, tirado por vacas, en España, es propio del área correspondiente a los vascones, várdulos, caristios, autrigones, cántabros, astures y galaicos, con repercusiones entre algunos de los habitantes de los Pirineos. El tipo de rueda más corriente es, también el de un travesaño de madera rectangular, con muy poco hierro ${ }^{41}$.

La bellota, la manteca de cerdo y las castañas eran elementos fundamentales de la dieta diaria. "Las gentes del norte tienen las castañas en alto sobre unas esteras tejidas con mimbres, porque no hay sustento que les dé más gusto ni que amen tanto excepto el vino, que comen y beben en platos y escudillas de palo. Las camas en que se acuestan son de palo, parecen andas de difunto, y no prueban el pan de trigo ni la carne frescos". La riqueza agrícola de la Lusitania se refleja también en la jactancia con que los lusitanos dijeron a Graco, cuando éste los amenazaba, que tenía provisiones para diez años. Semejante ostentación de riqueza se manifiesta también en los actos de la vida privada "este régimen alimenticio y casero, más o menos rústico o refinado, era el común a todos los pueblos del N. del Galicia o de Vasconia y estaba condicionado en parte por la geografía" ${ }^{42}$.

Dentro de la indumentaria gallega ha quedado el uso de la coroza, del latín crocea (amarillo), prenda primitiva propia de pueblos agrícolas, impermeable de juncos secos, que usan los aldeanos, y los zuecos, que sufren muchas variantes. La industria del lino tenía, en época romana, una importancia excepcional y siguió teniéndola hasta finales del XIII. Las mujeres se vestían con tejidos hechos de sustancias vegetales. Los hombres llevaban el pelo largo y flotante, aun cuando para combatir se ciñeran la frente con una banda. Las mujeres es probable que llevaran el pelo corto mientras eran doncellas y que de casadas se hicieran un tocado especial ${ }^{43}$.

40 PN, p. 184

${ }^{41}$ PN, pp. 152, 182-192. El autor resume a ARANZADI, «Aperos de labranzan, Folklore y costumbres de España (Barcelona: A. Martín, 1931), I, pp. 318-331.

42 PN, pp. 240-241; pp. 53-58, PE, I, p. 331. Cita: Cartas de Eugenio de Salazar, vecino y natural de Madrid, escritas a muy particulares amigos suyos (Madrid: Sociedad de Bibliófilos Españoles, 1866); EstraBóN, III, 3, 7.

43 PE, II, pp. 164-165. Cita: Plinio, HN, XIX, 2; "Del lino", Sem. de Agric. y Artes, III (1798), pp. 129-138, pp. 145-154; "Carta del cura de San Mamed de Sangueiros [...] 


\subsection{Religión}

Lo que dice sobre la religión de los gallegos, hay que leerlo a la luz de lo que nuestro autor piensa de la religión en general, que lo llevó a hacer duras críticas a otros autores que trataron este asunto. La religión no es un bloque dogmático, aunque así aparezca a los ojos de los teólogos, filósofos y juristas; para otras gentes es algo de tal riqueza de matices distintos y hasta contradictorios, que sorprende; de suerte que no puede reducirse tal fe a unas cuantas ideas, por profundas y esenciales que se consideren, ni a unas cuantas prácticas rígidas, ni a un puro balance negativo, fundado en dos o tres sentencias, más o menos antiguas y repetidas. Durkheim partió de una idea equivocada, por muy geométrica y exacta que parezca, como es la de equiparar una pretendida o manifiesta falta de complejidad social con una correspondiente simplicidad religiosa ${ }^{44}$.

Estrabón afirma que, las noches de plenilunio, los celtíberos y sus vecinos hacia el septentrión adoraban a un dios innominado, con grandes danzas a las puertas de sus casas. Era, sin duda, la luna, cuyo nombre no se podía pronunciar, a causa de los tabúes; este silencio de dios llevó a muchos a pensar que eran verdaderos ateos ${ }^{45}$. Cuando $\mathrm{N}$. Tenorio recorrió las aldeas gallegas sobre las que escribió su estudio, aún perduraba esta práctica, y Caro Baroja nos da cuenta de ello ${ }^{46}$ a pesar de que algunas partes de Galicia ya estaban cristianizadas con intensidad en el siglo IV, como lo revela el estudio de la cuestión priscilianista ${ }^{47}$.

Los orígenes de la religión cristiana en el NO de España hay que estudiarlos juntamente con la historia militar y económica de aquella zona. Todo hace pensar que el iter, camino de la nueva fe, era la vía XXXII que marcha de Astorga a Tarragona y no la XXXIV, que va de Astorga a Burdeos. Arqueólogos gallegos y portugueses han encontrado con frecuencia representaciones de serpientes en esculturas y grabados y han supuesto

sobre la industria y productos del lino", Sem. de Agric. y Artes, IV (1798), pp. 93-95 y V (1799), pp. 87-93; más datos en la misma revista, XI (1802), pp. 287-288 y XII (1802), pp. 131-143. El autor cita, además, X. LORENZO, «Notas etnográficas da terra de Loveira: o liño e a lá», Arg. do SEG, VI (1933-1934), pp. 25-84 y algunos otros.

44 J. CARO BAROJA, Las formas complejas de la vida religiosa (Madrid: Sarpe, 1985), p. 30. En este campo, su postura es muy crítica con la de E. DuRKhEIM, Les formes éleméntaires de la vie religieuse (Paris, 1912), cfr. Conversaciones en Itzea, op. cit., pp. 205-210.

45 ESTRABÓN, III, 4, 16.

46 N. Tenorio, La aldea gallega, op. cit., pp. 142-144, en PN, p. 252.

47 PN, p. 138. 
que tienen significado totémico. Caro Baroja no cree probada la hipótesis pero resalta, sin embargo, la importancia de la serpiente para aquellos pueblos del área ${ }^{48}$. ¿Sacrificaban machos cabríos, caballos e incluso hombres a un dios, en algún aspecto parecido a Ares o Marte? "Como generalizada en el Norte y acaso también entre los lusitanos, en un dios parecido en algún aspecto a Ares o Marte, dios al que se sacrificaban machos cabríos, caballos, e incluso hombres, haciéndose matanzas de gran cantidad de estas clases de víctimas en determinados momentos" ${ }^{49}$.

Estrabón, hablando de los lusitanos, dice que examinaban las vísceras sin separarlas del cuerpo, y adivinaban el futuro por el simple hecho de tocar las venas del pecho. Las vísceras de los prisioneros las auscultaban una vez cubiertas con sagos; hasta predecían por el modo cómo caía la víctima. También adivinaban por el vuelo de las aves; constata, también, que la creencia en meigas y brujas y en la santa compaña está muy extendida aún en nuestros días ${ }^{50}$.

Caro Baroja integró los detalles, fundamentalmente tomados de otros autores, dentro de una visión global de los pueblos del norte de España y los convirtió en piezas de un sistema coherente de pensamiento. Aquí sólo se ha tratado de dar unas cuantas pautas para interpretar lo que el autor de Los pueblos del Norte escribe sobre Galicia poniendo como ejemplo algunos casos concretos. Caro Baroja trata otros muchos aspectos relacionados con Galicia a los que en este trabajo ni siquiera se alude.

MANUEl MaNDianes CASTRO

CSIC. Barcelona

48 PE, I, p. 124; PN, pp. 231-233.

49 PE, I, p. 364.

50 PN, pp. 92-93; PE, II, p. 170; I, pp. 340, 365. El autor remite a J. RODRíGUEZ

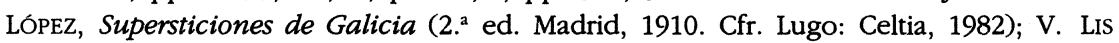
QuiBÉN, «Medicina popular gallega», RDTP, I (1944-1945), pp. 253-331, 694-722; V (1949), pp. 309-332 y 471-506. 
Julio Caro Baroja adopta la teoría de los ciclos histórico-culturales y el difusionismo de la escuela histórico-cultural de Viena. Está convencido de que, de la Península Ibérica, Galicia es la región que ha sufrido mayor influencia celta que aún perdura, pero no tanta como dicen los autores del Resurximento y de la Generación Nós. Por el contrario, cree que la romanización ha sido mayor de lo que dicen los mismos autores pero menor que la celtización.

Julio Caro Baroja adopted the difussionist theory of the historico-cultural circles of the Vienna school. He felt certain that, of all the regions in the Iberian Peninsula, Galicia was the most celtic, albeit less so than authors of the Resurximento and the Generacion Nós wanted us to believe. The impact of Romanization - played down by the same authors- was also important, second only to the celtic influence. 